\title{
Reoperative minimal access aortic valve surgery: Minimal mediastinal dissection and minimal injury risk
}

\author{
Minoru Tabata, MD, MPH, Zain Khalpey, MD, PhD, Prem S. Shekar, MD, and Lawrence H. Cohn, MD
}

\begin{abstract}
Objective: Minimizing surgical access in reoperative cardiac surgery allows limitation of dissection, trauma, and manipulation of patent bypass grafts. We report an 11-year experience with reoperative minimal access aortic valve surgery through an upper hemisternotomy.
\end{abstract}

\begin{abstract}
Methods: From July 1996 to June 2007 at our institution, 146 patients underwent reoperative minimal access aortic valve surgery, 109 of whom had undergone previous coronary artery bypass grafting and 93 of whom had a patent left internal thoracic artery graft. In patients with a patent left internal thoracic artery graft, the graft remained undissected. Myocardial protection was achieved with hypothermia, cold cardioplegia, and systemic hyperkalemia. Early and late outcomes were analyzed.
\end{abstract}

\begin{abstract}
Results: Median age was 76 years, and 43 patients (29\%) were 80 years or older. Nineteen patients(13\%) underwent concomitant procedures, such as coronary artery bypass grafting, mitral valve repair, and ascending aortic replacement. Median cardiopulmonary bypass and aortic crossclamp times were 150 and 80 minutes, respectively. Four patients $(2.8 \%)$ had conversion to full sternotomy. Operative mortality was $4.1 \%(6 / 146)$. The incidences of reoperation for bleeding and blood transfusion were $0.7 \%(1 / 146)$ and $83.6 \%(122 / 146)$, respectively. No patient had left internal thoracic artery or aortocoronary graft injury. Median stay was 8 days, and $56 \%(79 / 140)$ were discharged home. Five-year actuarial survival was $85 \%$.
\end{abstract}

Conclusion: An upper hemisternotomy approach for reoperative aortic valve surgery is safe and feasible. This approach minimizes tissue dissection and trauma, thereby reducing the risk of injury to patent grafts and mediastinal organs.

The frequency of reoperative cardiac surgery is increasing as patients live longer and more bioprosthetic valves are used. The major concerns in reoperative cardiac surgery are bleeding and mediastinal organ injury. Dissection of adherent tissue, the heart, and great vessels increases the amount of blood loss and subsequent blood transfusion requirement. During a reoperation after previous coronary artery bypass grafting (CABG), a key concern would be disturbing a patent, adherent coronary artery graft, particularly, the left internal thoracic artery (ITA) to left anterior descending artery graft, because this may lead to graft flow disruption, ischemia, dissection, or restenosis. Minimal access approaches minimize mediastinal dissection and handling of friable tissues on sternal reentry, resulting in reduced transfusion requirement and decreased operative time relative to a full sternotomy. ${ }^{1}$ For patients with patent grafts, this approach minimizes the risk of graft injury. left ITA grafts are not dissected, and other aortocoronary grafts are exposed only at their proximal part, which is usually identified without difficulty. ${ }^{2}$

From the Division of Cardiac Surgery, Brigham and Women's Hospital, Boston, Mass.

Received for publication April 25, 2008; revisions received July 21, 2008; accepted for publication July 28, 2008.

Address for reprints: Lawrence H. Cohn, MD, Division of Cardiac Surgery, Brigham and Women's Hospital, 75 Francis St, Boston, MA 02115 (E-mail: lcohn@partners. org).

J Thorac Cardiovasc Surg 2008; $136: 1564-8$

$0022-5223 / \$ 34.00$

Copyright (c) 2008 by The American Association for Thoracic Surgery doi:10.1016/j.jtcvs.2008.07.043
An upper hemisternotomy approach has been used at our institution since 1996 for reoperative aortic valve surgery. We sought to assess the early and late outcomes of reoperative minimal access aortic valve surgery (ReMAAVS).

\section{MATERIALS AND METHODS \\ Patient Data}

We conducted a retrospective review of 146 consecutive patients who underwent ReMAAVS between July 1996 and June 2007 at Brigham and Women's Hospital. In addition, we reviewed the cases of 150 patients who underwent isolated reoperative aortic valve surgery through a full sternotomy during the same period. Perioperative data were collected from patient medical records and the Brigham and Women's Hospital Cardiac Surgery Database according to The Society of Thoracic Surgeons National Adult Cardiac Database version 2.52 definitions. A hybrid procedure was defined as ReMAAVS within 24 hours after a percutaneous coronary intervention, and the detailed methodology has been previously published by our group. ${ }^{3}$ The number of transfused units of blood products was defined as the sum of blood products transfused from skin incision to discharge. Late survival data were collected from National Social Security Number Database. Continuous values are expressed as medians. This study was approved by the institutional review board of Brigham and Women's Hospital (protocol number 2005p000324), and a waiver of informed consent was obtained.

\section{Indications for ReMAAVS and Preoperative Assessment}

The reoperative upper hemisternotomy approach can be used for aortic valve and ascending aortic surgery. We successfully performed concomitant edge-to-edge repair of the mitral valve through the aortic annulus; however, this approach is not appropriate if a patient requires other concomitant procedures. We have performed a few cases of reoperative aortic root replacement through an upper hemisternotomy; however, we currently do not use this approach for reoperative aortic root replacement, because the exposure 


\section{Abbreviations and Acronyms \\ $\mathrm{CABG}=$ coronary artery bypass grafting \\ ITA $=$ internal thoracic artery \\ ReMAAVS $=$ reoperative minimal access aortic valve surgery \\ TEE $\quad=$ transesophageal echocardiography}

of the aortic root is difficult. Additionally, this approach would not be appropriate for a patient who cannot have a transvenous pacing wire (eg, mechanical tricuspid valve). In our institution, the approach selection (upper hemisternotomy vs full sternotomy) in reoperative aortic valve surgery largely depends on the surgeon's preference. Some surgeons exclusively use an upper hemisternotomy, whereas others use a full sternotomy.

Hybrid procedures were performed in selected high-risk patients with moderate coronary artery disease. Further follow-up is necessary, however, to establish the indications for a hybrid procedure. ${ }^{3}$

In patients with patent ITA grafts, we routinely performed a 3-dimensional computed assisted tomographic scan to assess the anatomic relationship between grafts and sternum. We used contrast medium unless a patient had renal insufficiency.

\section{Surgical Procedure of ReMAAVS}

All patients received external defibrillator pads, underwent intraoperative transesophageal echocardiography (TEE), and had a pulmonary arterial catheter with pacing ports placed unless specific contraindications existed. All patients underwent peripheral cannulation for cardiopulmonary bypass before resternotomy. Most patients underwent right axillary arterial and percutaneous femoral venous cannulation.

The upper sternum was divided down to the fourth intercostal space in the midline and then divided transversely to the right, at the fourth intercostal space. Cardiopulmonary bypass was started before the posterior sternal table was divided. Mediastinal dissection was limited to the ascending aorta for clamping and aortotomy, right atrial appendage for retrograde cardioplegia, and right superior pulmonary vein for venting. The in situ ITA grafts were not approached; only the proximal parts of the aortocoronary grafts were dissected. A retrograde cardioplegic cannula (under TEE guidance) and a venting cannula were placed (Figure 1).

On cardiopulmonary bypass, patients without a patent left ITA graft were systemically cooled to $28^{\circ} \mathrm{C}$ to $34^{\circ} \mathrm{C}$, and those with a patent left ITA graft were cooled down to $20^{\circ} \mathrm{C}$ to $25^{\circ} \mathrm{C}$. Cooling should be started after it is possible to place an aortic crossclamp. After standard aortic crossclamping, myocardial arrest was obtained with a combination of cold antegrade and retrograde cardioplegia with additional systemic hyperkalemia. Systemic hyperkalemia was accomplished by instilling potassium chloride into the cardiopulmonary bypass circuit and was maintained at a level of 6.0 to $7.0 \mathrm{mEq} / \mathrm{L}$. Ultrafiltration was used to clear the high level of potassium after release of the aortic crossclamp. Left ventricular distention was continuously monitored with TEE. Left ventricular venting was accomplished through the right superior pulmonary vein or through the aortic annulus after aortotomy. The aortic valve operation was then performed with standard techniques according to patient indications (Figure 2). When backflow from the patent left ITA-left anterior descending artery graft through the left main ostium obscured the operative field, pump flows were temporarily turned down to improve surgical field view. Rewarming was started after the aortic valve was seated. The aortotomy was closed, and the aortic crossclamp was released.

Defibrillation was achieved through the external pads. In addition to standard deairing maneuvers, external compressions and table positioning helped in removal of intracardiac air, as confirmed by TEE. Carbon dioxide was blown in the mediastinal space during aortic crossclamping to minimize
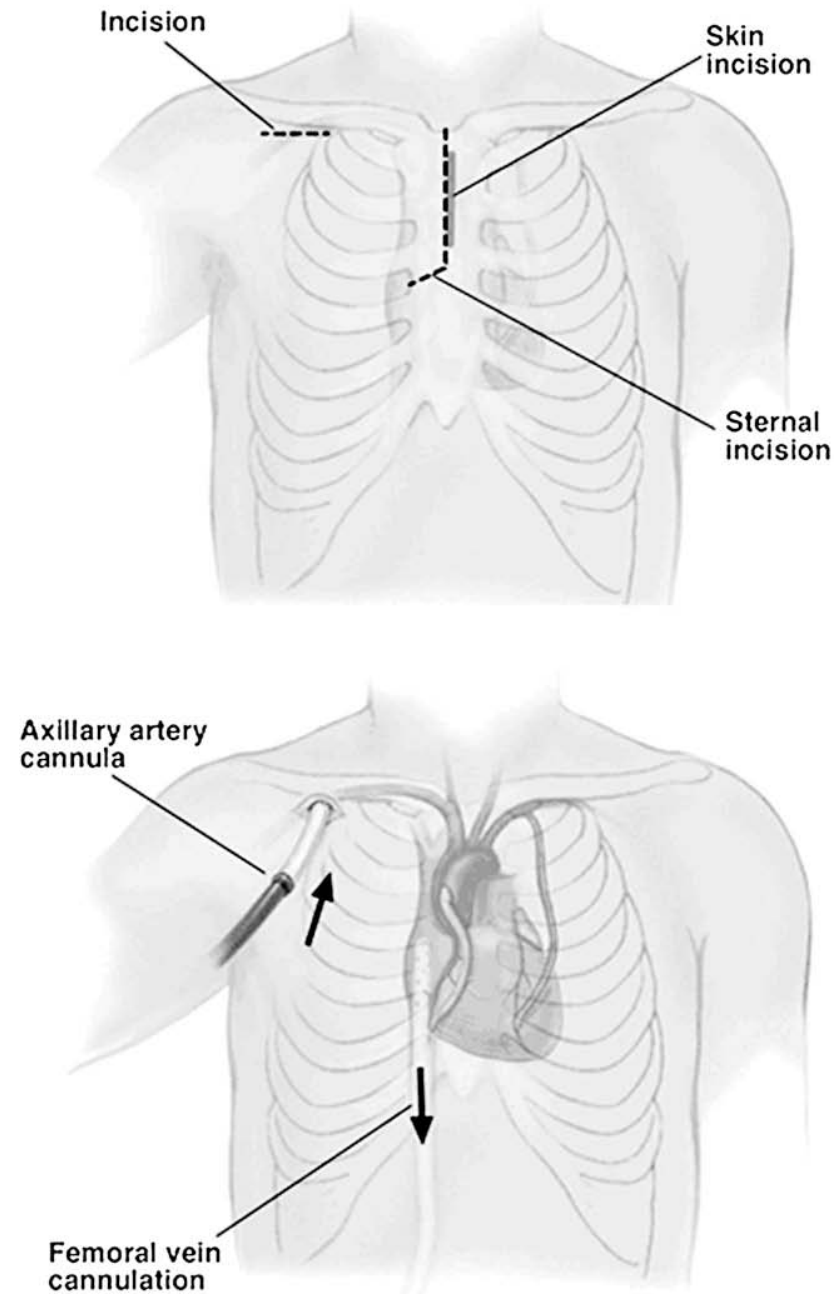

FIGURE 1. Skin and sternal incisions (top) and cannulation (bottom) in reoperative minimal access aortic valve surgery.

the risk of air embolism. ${ }^{4}$ Temporary epicardial pacing wires were placed on the anterior surface of the right ventricle before the aortic crossclamp was removed, with the heart completely decompressed if possible. In most cases, we placed transvenous pacing electrodes through the pulmonary artery catheter. All patients received drainage tubes placed through the right pleural space. Cardiopulmonary bypass weaning, decannulation, and chest closure were done in a standard fashion.

\section{RESULTS}

\section{Preoperative Characteristics}

Median patient age was 76 years (range 27-93 years), and 43 patients $(29 \%)$ were 80 years old or older. Among 146 patients, 109 had previously undergone $\mathrm{CABG}$, and 93 had patent left ITA grafts. Other preoperative characteristics of patients are shown in Table 1.

\section{Operative Variables}

One hundred thirty-seven patients underwent stented aortic bioprosthetic valve replacements, 37 underwent mechanical valve replacements, 3 underwent stentless aortic 


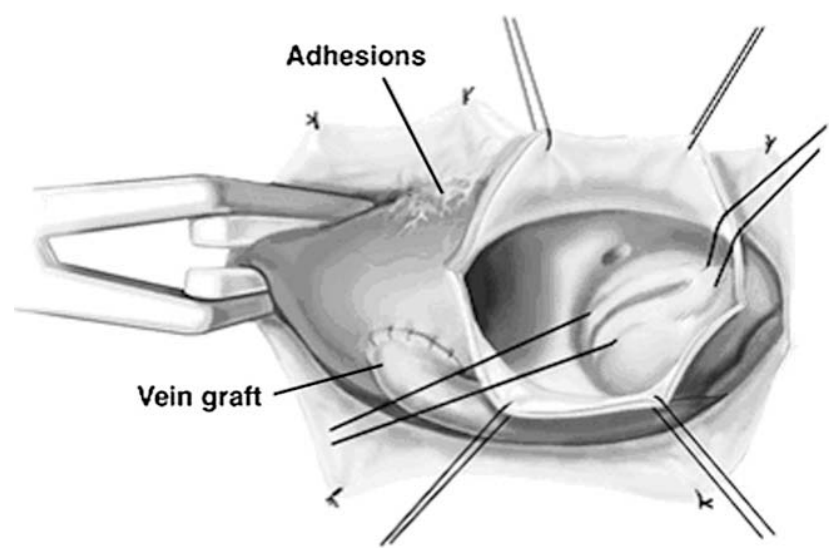

FIGURE 2. Aortic valve exposure in reoperative minimal access aortic valve surgery (surgeon's view).

bioprosthetic valve replacements, and 1 underwent an aortic valve repair. Six patients underwent hybrid procedures, 5 underwent annular enlargement, 5 underwent concomitant mitral valve repair (edge-to-edge repair through the aortic valve annulus), and 4 underwent concomitant ascending aortic replacement. Four patients $(2.7 \%)$ had conversion to a full sternotomy during surgery. The reasons for conversion included poor exposure of the aortic valve, right ventricular tear from pacing wire placement, right ventricular failure, and sustained ventricular fibrillation after release of the aortic crossclamp. The median cardiopulmonary bypass and aortic crossclamp times were 150 and 80 minutes, respectively (including nonisolated aortic valve operations). In a subgroup of patients with patent left ITA grafts who had systemic hyperkalemia, intraoperative hemofiltration was almost routinely used to clear high potassium level; however no patient required new postoperative dialysis.

\section{Early and Late Outcomes}

The operative mortality was $4.1 \%(6 / 146)$. There were 5 cardiac deaths and 1 neurologic death. There was no incidence of left ITA or aortocoronary graft injury. The incidences of postoperative complications and blood transfusion requirements are shown in Table 2. The bleeding site

TABLE 1. Preoperative patient characteristics $(N=146)$

Age (y, median and range)

$76(27-93)$

Male (No.)

$115(78.8 \%)$

More than 1 previous operation (No.)

Previous coronary artery bypass grafting (No.)

$13(8.9 \%)$

$109(74.7 \%)$

Patent internal thoracic artery graft (No.)

Previous aortic valve replacement (No.)

Ejection fraction ( $\%$, median and range)

Nonelective surgery (No.)

Aortic stenosis (No.)

Aortic insufficiency (No.)

Aortic stenosis and insufficiency (No.)
TABLE 2. Operative outcomes

\begin{tabular}{lcc}
\hline \multicolumn{1}{c}{ Variable } & $\begin{array}{c}\text { All patients } \\
(\mathbf{n = 1 4 6 )}\end{array}$ & $\begin{array}{c}\exists \mathbf{8 0} \mathbf{y} \\
(\mathbf{n = 4 3})\end{array}$ \\
\hline Operative death (No.) & $6(4.1 \%)$ & $1(2.3 \%)$ \\
Graft injury (No.) & $0(0 \%)$ & $0(0 \%)$ \\
Reoperation for bleeding (No.) & $1(0.7 \%)$ & $1(2.3 \%)$ \\
Deep sternal wound infection (No.) & $1(0.7 \%)$ & $0(0 \%)$ \\
Prolonged postoperative & $21(14.4 \%)$ & $9(20.9 \%)$ \\
$\quad$ ventilation (>24 h, No.) & $3(2.1 \%)$ & $0(0 \%)$ \\
Pneumonia (No.) & $122(83.6 \%)$ & $39(90.7 \%)$ \\
Blood transfusion (No.) & $115(78.8 \%)$ & $37(86.0 \%)$ \\
Red blood cell transfusion & 3 & 4 \\
$\quad$ Patients transfused (No.) & & $15(34.9 \%)$ \\
$\quad$ Median transfusion (units) & $69(47.3 \%)$ & 2 \\
Fresh-frozen plasma transfusion & 3 & $13(30.2 \%)$ \\
$\quad$ Patients transfused (No.) & & 6 \\
$\quad$ Median transfusion (units) & $47(32.2 \%)$ & \\
Platelet transfusion & 6 & \\
$\quad$ Patients transfused (No.) & &
\end{tabular}

of 1 patient who required reexploration was the right ITA. Median hospital stay was 8 days, and 56\% (79/140) were discharged directly home. Five-year actuarial survival was $85 \%$.

In the elderly subgroup ( $\geq 80$ years old), the operative mortality was $2.3 \%(1 / 43)$. The incidences of postoperative complications and blood transfusion requirements are shown in Table 2. Median stay in this subgroup was 9 days, and $33.3 \%(14 / 42)$ were discharged directly home.

\section{Full Sternotomy Approach}

We used a full sternotomy approach in 150 reoperative isolated aortic valve operations. Among these cases, 62 patients had previously undergone $\mathrm{CABG}$, and 50 had patent ITA grafts. In those cases, the mediastinal dissection was minimized, and ITA grafts were not approached..$^{5}$ Median age was 68 years (range 20-90 years). Median cardiopulmonary bypass and aortic crossclamp times were 145 and 83 minutes, respectively (including only isolated aortic valve operations). The operative mortality was $4.6 \%$ (7/150), and the blood transfusion requirement rate was $83.3 \%$ $(125 / 150)$. There were 3 left ITA graft injuries at the time of sternal entry or mediastinal dissection.

\section{DISCUSSION}

Our 11-year, single-institution experience of ReMAAVS indicates that a minimal access approach is safe and feasible for reoperative aortic valve surgery. The benefits of a minimal access approach in aortic valve operations include shorter stay, ${ }^{6-9}$ more discharges directly to home,${ }^{6-8}$ less incisional pain, ${ }^{10,11}$ shorter duration of ventilation, ${ }^{7,8,10}$ and less blood $\operatorname{loss}^{7-10,12}$ and blood transfusion ${ }^{8}$ than with a full sternotomy. Avoiding a full sternotomy should 
contribute to better postoperative stability of the sternum and less incisional pain. Better-preserved stability of the sternum may prevent deep infection, help recovery of respiratory function, and aid in early mobility in the immediate postoperative period. ${ }^{13}$ Our data indicate low incidences of deep sternal wound infection and pneumonia, which would support this assumption. Furthermore, a minimal access approach in reoperative surgery provides additional benefits, such as minimizing the risk of injury to mediastinal organs and patent grafts. Our series did not have any left ITA or aortocoronary graft injuries. We had no mediastinal organ injuries during reoperative sternotomy and dissection. In full sternotomy cases, even though we minimized the mediastinal dissection and did not approach the left ITA graft, there were some left ITA graft injuries. Because the mediastinal organs or patent grafts can be very close to the upper sternum, we further recommend a routine assessment of the geographic and anatomic relations of grafts by imaging. Grafts may lie in unusually close proximity to critical structures that may need to be dissected or divided during the operation. As we described here, we routinely perform 3dimensional computed assisted tomography before surgery, which is very useful in showing the anatomic relationship between patent grafts and sternum for building the surgical strategy. ${ }^{14}$

In our series, the blood transfusion rate with a minimal access approach was relatively high, similar to that with a full sternotomy approach. This finding does not support the conjecture that a minimal access approach reduces bleeding or blood transfusion requirement. The high blood transfusion rate could be explained by the longer cardiopulmonary bypass times during a partial sternotomy and systemic hypothermia (especially in patients with a patent ITA graft).

Myocardial protection in patients with patent left ITA grafts was obtained during cardiac asystole with systemic cooling, antegrade and retrograde cardioplegia, and systemic hyperkalemia. Retrograde cardioplegia is essential in patients with previous CABG. In a nonreoperative situation, we occasionally abort placement of retrograde cardioplegia cannula to avoid coronary sinus injury. ${ }^{15}$ In a reoperative situation, coronary sinus injury is unlikely to occur because of fibrous adhesion of the posterior heart.

Limited access may provide insufficient exposure of the aortic valve. In our series, we had only 1 case that required conversion to a full sternotomy because of poor exposure. We saw right ventricular injury from pacing wire placement, which required conversion to a full sternotomy for repair. We therefore now avoid placement of epicardial pacing wires and routinely use a pulmonary artery catheter with pacing ports. It is difficult to use internal defibrillation paddles in reoperative minimal access procedures. Appropriate and accurate positioning of external pads is thus extremely important. We had 4 converted cases $(2.7 \%)$. In our entire minimal access experience with an upper hemisternotomy, the conversion rate was $2.6 \%$ to $2.7 \% .^{13,15}$ This reoperative conversion rate is similar to that seen with a primary minimal access aortic valve surgical approach.

There have been a limited number of reports of ReMAAVS. Bakir and colleagues ${ }^{16}$ reported on 19 cases of reoperative aortic valve replacement through an upper hemisternotomy and showed favorable results. Their surgical strategy was almost the same as ours, except that they often used central aortic cannulation. Sharony and colleagues ${ }^{17}$ reported on reoperative valve operations through a minithoracotomy, including 61 aortic valve operations. In their study, the minimal access group had similar cardiopulmonary and aortic crossclamp times, a lower incidence of wound infection, and a shorter hospital stay than the full sternotomy group.

A limitation of this study is its noncomparative nature. We did not statistically compare our ReMAAVS outcomes with those of conventional reoperative aortic valve surgery, because the approach selection was strongly surgeon specific and it was difficult to properly adjust this confounding factor.

In conclusion, a minimal access approach is safe and feasible in reoperative aortic valve surgery, with excellent early and late outcomes. This approach minimizes tissue dissection and trauma, thereby reducing the risk of injury to patent grafts and mediastinal organs.

We thank Siobhan McGurk, who assisted us with data collection and management.

\section{References}

1. Byrne JG, Aranki SF, Couper GS, Adams DH, Allred EN, Cohn LH. Reoperative aortic valve replacement: partial upper hemisternotomy versus conventional full sternotomy. J Thorac Cardiovasc Surg. 1999;118:991-7.

2. Byrne JG, Karavas AN, Adams DH, Aklog L, Aranki SF, Couper GS, et al. Partial upper re-sternotomy for aortic valve replacement or re-replacement after previous cardiac surgery. Eur J Cardiothorac Surg. 2000;18:282-6.

3. Brinster DR, Byrne M, Rogers CD, Baim DS, Simon DI, Couper GS, et al. Effectiveness of same day percutaneous coronary intervention followed by minimally invasive aortic valve replacement for aortic stenosis and moderate coronary disease ("hybrid approach"). Am J Cardiol. 2006;98:1501-3.

4. Selman MW, McAlpine WA, Albregt H, Ratan R. An effective method of replacing air in the chest with $\mathrm{CO}_{2}$ during open heart surgery. $J$ Thorac Cardiovasc Surg. 1967;53:618-22.

5. Byrne JG, Karavas AN, Filsoufi F, Mihaljevic T, Aklog L, Adams DH, et al. Aortic valve surgery after previous coronary artery bypass grafting with functioning internal mammary artery grafts. Ann Thorac Surg. 2002;73:779-84.

6. Mihaljevic T, Cohn LH, Unic D, Aranki SF, Couper GS, Byrne JG. One thousand minimally invasive valve operations. Early and late results. Ann Surg. 2004;240: 529-34.

7. Liu J, Sidiropoulos A, Konertz W. Minimally invasive aortic valve replacement (AVR) compared to standard AVR. Eur J Cardiothorac Surg. 1999;16(Suppl. 2):S80-3.

8. Bonacchi M, Prifti E, Giunti G, Frati G, Sani G. Does minsternotomy improve postoperative outcome in aortic valve operation? A prospective randomized study. Ann Thorac Surg. 2002;73:460-6.

9. Bakir I, Casselman FP, Wellens F, Jeanmart H, De Geest R, Degrieck I, et al. Minimally invasive versus standard approach aortic valve replacement: a study in 506 patients. Ann Thorac Surg. 2006;81:1599-604.

10. Mächler HE, Bergmann P, Anelli-Monti M, Dacar D, Rehak P, Knez I, et al. Minimally invasive versus conventional aortic valve operations: a prospective study in 120 patients. Ann Thorac Surg. 1999;67:1001-5. 
11. Candaele S, Herijgers P, Demeyere R, Flameng W, Evers G. Chest pain after partial upper versus complete sternotomy for aortic valve surgery. Acta Cardiol. 2003;58:17-21.

12. Dogan S, Dzemali O, Wimmer-Greinecker G, Derra P, Doss M, Khan MF, et al. Minimally invasive versus conventional aortic valve replacement: a prospective randomized trial. J Heart Valve Dis. 2003;12:76-80.

13. Tabata M, Umakanthan R, Cohn LH, Bolman RM, Shekar PS, Chen FY, et al. Early and late outcomes of 1000 minimally invasive aortic valve operations. Eur J Cardiothorac Surg. 2008;33:537-41.

14. Gasparovic H, Rybicki FJ, Millstine J, Unic D, Byrne JG, Yucel K, et al. Three dimensional computed tomographic imaging in planning the surgical approach for redo cardiac surgery after coronary revascularization. Eur J Cardiothorac Surg. 2005;28:244-9.

15. Tabata M, Umakanthan R, Khalpey Z, Couper GS, Aranki SF, Cohn LH, et al. Full sternotomy conversion following minimal access cardiac surgery: reasons and results during a 9.5-year experience. J Thorac Cardiovasc Surg. 2007;134:165-9.

16. Bakir I, Casselman FP, De Geest R, Wellens F, Degrleck I, Van Praet F, et al. Should minimally invasive aortic valve replacement be restricted to primary interventions? Thorac Cardiovasc Surg. 2007;55:304-9.

17. Sharony R, Gross EA, Saunders PC, Schwartz CF, Ursomanno P, Ribakove GH, et al. Minimally invasive reoperative isolated valve surgery: early and mid-term results. J Card Surg. 2006;21:240-4. 